\title{
Analysis of Research Directions in the Field of Library Intelligence from the Perspective of Altmetrics
}

\author{
Xiaotao Li ${ }^{1}$, Xiaoqing Xia ${ }^{1,2}$ \\ ${ }^{1}$ Nanjing University of Aeronautics and Astronautics, Nanjing, China \\ ${ }^{2}$ Pujang College, Nanjing University of Technology, Nanjing, China \\ Email: 845447805@qq.com
}

How to cite this paper: Li, X.T. and Xia X.Q. (2021) Analysis of Research Directions in the Field of Library Intelligence from the Perspective of Altmetrics. Intelligent Information Management, 13, 169-179. https://doi.org/10.4236/iim.2021.133009

Received: March 15, 2021

Accepted: April 9, 2021

Published: April 12, 2021

Copyright () 2021 by author(s) and Scientific Research Publishing Inc. This work is licensed under the Creative Commons Attribution International License (CC BY 4.0).

http://creativecommons.org/licenses/by/4.0/ (c) (i) Open Access

\begin{abstract}
With the continuous development of science and technology, the academic communication of many scholars slowly shifts to the web, and people's academic communication in social media gradually increases. Traditional metrics have a certain one-sidedness in the evaluation of disciplinary literature and cannot evaluate the impact of literature on the web; while Altmetrics can count how literature is followed and utilized on the web, which is a complement to the traditional measurement methods. Therefore, it is necessary to evaluate the impact of academic literature based on Altmetrics, and combining it with traditional citation indicators can strengthen the credibility and objectivity of academic evaluation and promote better dissemination and communication of academic results. Against this research background, this paper combed through the most influential articles in the field of library and information science in recent years, analysed the literature on library intelligence in the WOS database, identified current research hotspots in the field of library and information science, and predicted potential research hotspots in the future. This study may provide a reference for the research and development of the discipline.
\end{abstract}

\section{Keywords}

Altmetrics, Library and Information Science, Research Hotspots

\section{Introduction}

\subsection{Concept of Altmetrics}

Altmetrics is a new term that emerged after bibliometrics, informetrics, and we- 
bometrics, and its emergence has a kind of inevitability: first, scholars are increasingly using the web for scholarly communication and tracking; second, the general public can also participate in the academic community online; and third, the development of open access and open scholarship has made online scholarly communication mainstream altmetrics. The emergence of Altmetrics means a new world of metrology. It is actually an abbreviation of "alternative metrics", which was first used as a hashtag by Priem on Twitter in 2010, and then by Priem, Taraborelli, Groth and Neylon on their website Altmetrics.org published a manifesto to formally introduce Altmetrics and describe the development of Altmetrics, launching a global academic movement advocating Altmetrics [1]. Altmetrics metrics, which include digital web data metrics for many forms of scholarship, are an important part of Altmetrics research and can be seen as a medium for Altmetrics applications across disciplines. A variety of Altmetrics metrics have been developed based on different data sources on the web including news, blogs, policies, patents, Twitter, peer review, Facebook, Wikipedia, LinkedIn, Reddit, Pinterest, F1000, Q \& A, videos, syllabi, Mendeley Dimension, etc. There are currently many platforms for online Altmetrics data sources, including Altmetric Explorer, PLoS ALM, Bookmetrix, PlumX Dashboard, ImpactStory.

\subsection{Review of the Current Status of Domestic and International Research}

The first domestic research related to library science and intelligence began in 1980, mainly introducing the development of the field of library intelligence abroad, including journal publication and education; it also introduced some related research activities in the field of library and information science in China at that time. Later, with the continuous development of the discipline, research in library intelligence and its academic results have received more and more attention and concern from the academic community, and people in the field began to focus on summarizing and analyzing the hot topics of research in related disciplines. In China, there are studies for foreign language papers [2] [3] [4], Chinese journal papers [5] [6] [7], and studies for the National Social Science Foundation projects [8] [9]. The identification of research themes in the field of library intelligence has been carried out earlier abroad, and more types of hot research analysis methods are used: content analysis [10], LDA theme analysis [11] [12], co-word analysis [13] [14] [15], and so on. The advantage of content analysis is that the findings are objective and not influenced by the subjective attitude of the researcher, but the disadvantage is that this method can only analyze the explicit communication content, and the intrinsic validity is not high; the advantage of LDA thematic analysis is that it has a clearer purpose and can better reflect the differences between samples, but the disadvantage is that this method is not suitable for short text analysis, and the model effect is not good. The advantage of co-word analysis is that it can go deeper into the literature to reflect the research themes, but the disadvantage is that it is not conducive to the 
discovery of potential research hotspots.

Throughout the above studies, it is found that the hotspot studies in the field of library intelligence at home and abroad have achieved certain results, which are of high reference value for understanding the development of the field of library and information science, and their research methods have a certain guiding role for other scholars to conduct relevant research. However, in recent years, domestic hotspot analyses in the field of library and information science have been basically conducted from the perspective of academic influence; while foreign studies on the field of library and information science are mostly based on a certain data object of academic results, lacking multi-dimensional analysis of different carriers and platforms, and the research results are one-sided. Coupled with the fact that the previous studies were conducted for specific time periods or specific data sources relatively early in time, they have certain limitations. With the passage of time, the development of the discipline has new research directions, and it is important to identify the discipline research hotspots in recent years. The main purpose of this paper is to construct a new comprehensive influence evaluation system, which integrates the academic influence and social influence of academic results to identify the research hotspots in the field of library and information science during 2017-2019, to help the industry understand the current research dynamics in the field of library and information science in a timely manner and provide a reference for future work.

\section{Altmetrics-Based Evaluation of the Impact of Papers in the Field of Library and information science}

\subsection{Altmetrics Metrics Data Acquisition}

In this paper, using Web of Science as the data source, the search condition was set to "wc = information science library science", and the DOI number was used in batches at Altmetric.com to obtain the Altmetrics The Altmetrics index data and attention scores of 8283 documents were finally obtained. SPSS was used to select the six indicators of cited frequency, Mendeley, Twitter, Dimensions, Facebook, and Blog to establish a comprehensive influence evaluation index system for disciplines in the field of library and information science. The formula of comprehensive influence score was obtained by using SPSS: $\mathrm{F}$ comprehensive $=$ $\left(\mathrm{F}\right.$ academic ${ }^{*} 0.4454+\mathrm{F}$ social $\left.{ }^{\star} 0.2508\right) / 0.6962$.

According to the famous American historian of science George Price's Price's law proposed by the famous American historian George Price, the top 50\% (4141) of the literature with a high comprehensive influence score was selected as the object of study for the next analysis.

\subsection{Analysis of the Years of Publication and Authors of High-Impact Papers in the Field of Library and Information Science}

As shown in Figure 1, 1788 of the 4141 papers were published in 2017, accounting 


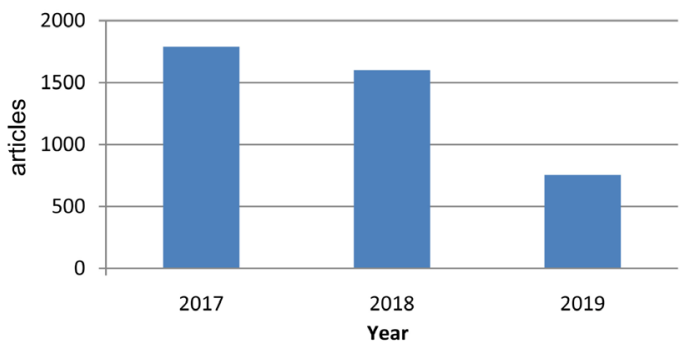

Figure 1. Publication years.

for 43.18\%; 1598 were published in 2018, accounting for 38.59\%; and 755 were published in 2019, accounting for only $18.23 \%$. As can be seen from the figure, the selected sample has a smaller proportion of 2019, which may be related to the recent years of publication.

Then, the authorship data of these papers were imported into the software VOS viewer, and the results from the run showed that a total of 11,016 authors were involved in the publication of high-impact papers. Price's law can be expressed in the formula as:

$$
\sum_{m+1}^{I} n(x)=\sqrt{N}
$$

where $n(x)$ is the number of authors who have published $x$ papers; $I=n_{\max }$ indicates the most number of papers published by the core authors in the field; $\mathrm{m}=$ $0.749\left(n_{\max }\right) 0.5$, the least number of papers published by the core authors; and $N$ is the total number of all authors in the field [16]. According to this law, by substituting the number of 32 papers with the highest number of research publications in the field of library and information science and the total number of authors 11016 into the formula, the core authors in the field of library and information science can be identified as those authors with more than 4 publications. The authors with more than 4 publications are 174 scholars, who have published 1029 papers, accounting for $24.85 \%$ of the total number of papers. These are the core authors in the field of library and information science (Table $1)$.

The most published author is Thelwall Mike, a professor from the University of Wolverhampton, with 32 publications; other authors with more publications are Bornmann Lutz, Leydesdorff Loet, and Abramo Giovanni, with 31, 18, and 14 publications respectively.

\subsection{Analysis of the Situation of Related Journals}

Continuing the hierarchical cluster analysis of the 6 indicators (frequency cited, Mendeley, Twitter, Dimensions, Facebook, and Blog) of the 4141 data using the software SPSS, a clustering dendrogram was obtained (Figure 2), and taking $\mathrm{d}=$ 5 , these journals can be classified into 4 categories.

The first category is Scientometrics and Journal of the American Medical Informatics Association, two journals with high Altmetrics scores and many citations, which also have high social and academic influence. 


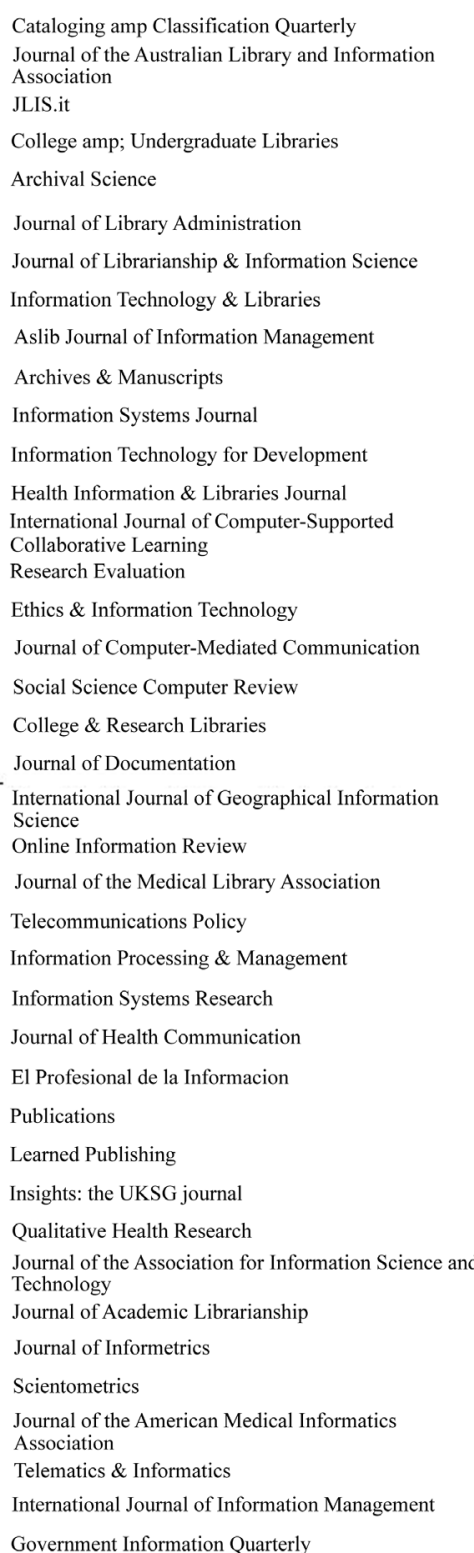

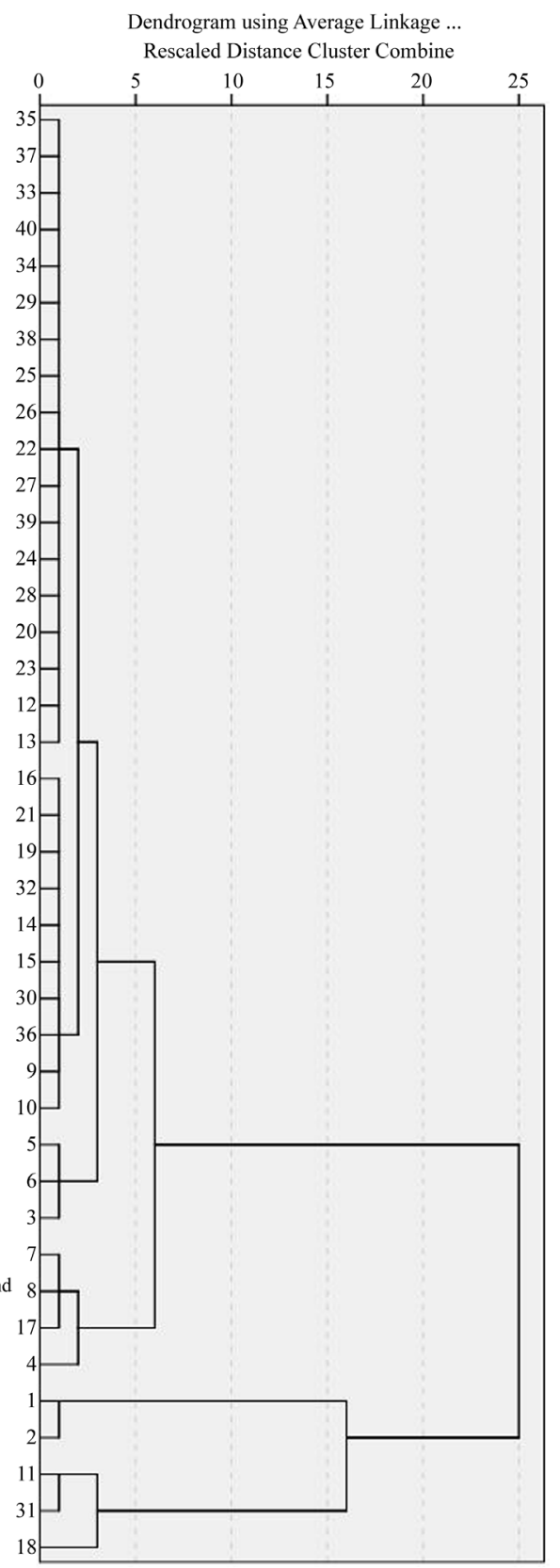

Figure 2. Indicator clustering tree diagram.

The second category is more numerous and contains 31 journals; these journals are less cited and less mentioned by Mendeley.

The third category is the Journal of Informetrics, Qualitative Health Research, Journal of the Association for Information Science and Technology, and Journal 4 journals of Academic Librarianship, which have high Altmetrics scores and few citations.

The fourth category is Telematics \& Informatics, Government Information Quarterly and International Journal of Information Management 3 journals, these 3 journals Mendeley mentioned the the highest number of times. 
Table 1. Ranking of authors of publications.

\begin{tabular}{|c|c|c|}
\hline Author & Number of articles & Cited \\
\hline Thelwall Mike & 3 & 254 \\
\hline Bornmann Lutz & 3 & 157 \\
\hline Leydesdorff Let & 18 & 87 \\
\hline Abramo Giovnn & 4 & 1 \\
\hline Machin-mastromatteo Juan d. & 14 & 7 \\
\hline Haunschild Roin & 3 & 5 \\
\hline D’angelo C iriaco & 12 & 41 \\
\hline Dwivedi Yogesh k. & 2 & 7 \\
\hline Da silva Jaime a. Teixeira & 11 & 47 \\
\hline Orduna-malea Enriqe & 11 & 139 \\
\hline Pinfield Stephen & 11 & 83 \\
\hline Kousha Kayvan & 10 & 44 \\
\hline Rana Nripendra p. & 10 & 290 \\
\hline Wright Adam & 10 & 35 \\
\hline Bates David w. & 9 & 62 \\
\hline Costas Rodrigo & 9 & 42 \\
\hline Delgado Lopez-cozar Emilio & 9 & 146 \\
\hline Lowry Paul Benjamin & 9 & 59 \\
\hline Martin Alberto & 9 & 146 \\
\hline Nicholas David & 9 & 104 \\
\hline
\end{tabular}

\subsection{Country/Region and Language Analysis}

Next, the countries/regions involved in the publication of these 4141 documents were analyzed. The authors of these papers came from 113 countries and regions around the world. The text data were imported into VOS Viewer again, and the analysis type was selected as Countries, with the threshold set to 5 (selecting the countries with at least 5 published papers), and the following Figure 3 was obtained.

There are 68 countries with more than 5 publications and 53 countries with more than 10 publications. The VOS Viewer list information was exported, and some of them were selected as Table 2 .

As can be seen from the table, the United States has the largest collaborative impact in the field of library and information science and is the leading research country in the field of library and information science with 1605 publications, accounting for $19.38 \%$ of the global total and 6878 citations followed by the United Kingdom, China, Spain, Australia, Canada, and Germany, which account for $6.30 \%, 4.03 \%, 3.78 \%, 3.43 \%, 2.98 \%$, and $2.76 \%$ of the global total, respectively. In terms of language distribution, the statistics show that the number of articles 


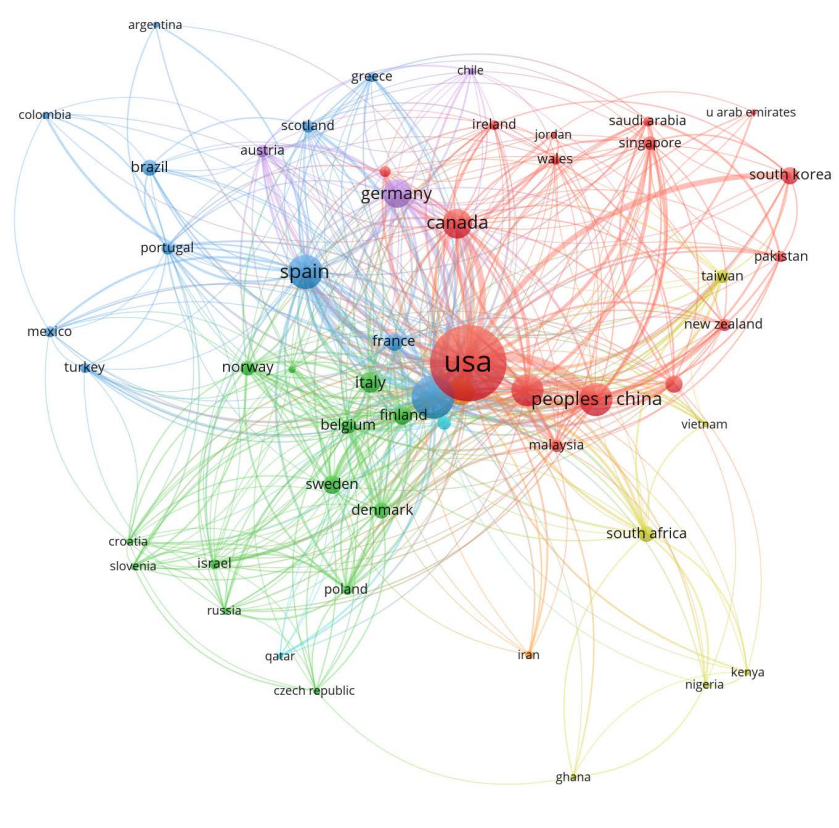

今 vosviewer

Figure 3. Country cooperation impact.

Table 2. Number of national publications.

\begin{tabular}{cccccc}
\hline Countries & $\begin{array}{c}\text { Number of } \\
\text { articles issued }\end{array}$ & Quotations & Countries & $\begin{array}{c}\text { Number of } \\
\text { articles issued }\end{array}$ & Quotations \\
\hline USA & 1605 & 6878 & Finland & 94 & 592 \\
England & 522 & 2445 & India & 83 & 410 \\
$\begin{array}{c}\text { China } \\
\text { (including Taiwan) }\end{array}$ & 371 & 2450 & South Korea & 82 & 435 \\
Spain & 334 & 1407 & The French & 81 & 437 \\
Australia & 284 & 1379 & The Danish & 75 & 388 \\
Canada & 247 & 1028 & Brazil & 71 & 226 \\
Germany & 229 & 1033 & South Africa & 70 & 268 \\
Germany & 189 & 1244 & Belgium & 61 & 348 \\
Italy & 132 & 674 & The Norwegian & 61 & 284 \\
Swedish & 95 & 381 & Singapore & 56 & 424 \\
\hline
\end{tabular}

published in the UK, China, Spain, Australia, Canada and Germany accounted for $6.30 \%, 4.03 \%, 3.78 \%, 3.43 \%, 2.98 \%$ and $2.76 \%$ of the global total respectively.

In terms of language distribution, the statistics show that the most frequent language in the selected sample is English literature 3986 (96.26\%), followed by Spanish $102(2.46 \%)$, as well as Portuguese 29 (0.70\%), Italian 18 (0.43\%), German $5(0.12 \%)$, and French 1. This indicates that English is the main international language spoken in the world today and has an advantage in academic communication. 


\subsection{Analysis of Research Hotspots in the Field of library and information science}

This section analyzes the keywords of high-impact papers in the field of library and information science with high-frequency words, cluster analysis, and makes some suggestions for the future development of the field of library intelligence.

The 10,459 keywords of the above 4141 documents were selected for analysis, and 567 keywords with the number of occurrences above 5 were listed in descending order according to the number of occurrences of these high-frequency keywords, and some of them were selected to obtain Table 3.

The keywords in the table can be roughly divided into four categories: the first category is the research of econometrics, including bibliometrics, open access, qualitative, altmetrics, citation analysis, scholarly communication, research evaluation, qualitative research, web of science, scientometrics, peer review; the second category is the theme of social network communication, including social media, twitter, machine learning knowledge management, facebook, e-government, natural language processing, knowledge sharing, literature review, case study; the third category is about library research, including academic libraries, collaboration, libraries, Canada, higher education; the fourth category is research on other topics, including information literacy, electronic health records, big data, and ethics.

These clusters constitute the research hotspots in the field of library and information science in the past three years. After content analysis of the relevant

Table 3. Keyword list.

\begin{tabular}{cccc}
\hline Keyword & $\begin{array}{c}\text { Frequency of } \\
\text { occurrence }\end{array}$ & Keyword & $\begin{array}{c}\text { Frequency of } \\
\text { occurrence }\end{array}$ \\
\hline social media & 190 & collaboration & 42 \\
bibliometrics & 111 & ethics & 40 \\
open access & 111 & facebook & 39 \\
qualitative & 107 & qualitative research & 39 \\
academic libraries & 103 & web of science & 38 \\
twitter & 87 & e-government & 37 \\
altmetrics & 73 & scientometrics & 37 \\
information literacy & 66 & natural language processing & 36 \\
citation analysis & 57 & peer review & 36 \\
electronic health records & 57 & libraries & 35 \\
machine learning & 52 & knowledge sharing & 33 \\
big data & 50 & canada & 32 \\
scholarly communication & 50 & higher education & 31 \\
knowledge management & 46 & literature review & 30 \\
research evaluation & 46 & case study & 29 \\
\hline
\end{tabular}


literature for each cluster, together with the previous research results, 10 research hotspots in the field of library and information science were concluded: research related to Altmetrics, open access status and its impact on related industries, application analysis about big data, utilization of government data, application research of social media, and information systems in various industries, the practical use of dynamic capabilities, new directions in citation analysis, data sharing case studies and problems, and the impact of digital innovation on businesses, policies, etc.

In fact, these 10 research hotspots summarized in this study are not completely isolated and cross-researched with each other: Altmetrics and citation analysis are often discussed together, Big Data research inevitably involves social media, information systems, and government data is actually part of Big Data. There are still many problems to be solved in these research areas, such as narrow research scope, incomplete selection of data, no formation of the same specification, etc. Further research using new theories and techniques is needed.

\section{Suggestions for the Future of Library Intelligence}

By analyzing the emerging areas (literature with high Altmetrics index scores and few citations), these aspects such as aging issues, robotics and artificial intelligence, blockchain, machine learning and network ecosystem will be the focus and hotspots of research in the field of library and information science in the coming years. With the rapid development of network information technology, the future of the field of library and information science will face new opportunities and challenges. Ma Fei-Cheng et al. analyzed the development prospects of China's library intelligence discipline in the context of the new liberal arts [17], and combined with this study, they concluded that the future research in library intelligence needs to start from the following aspects.

The first is a humanistic concern oriented to the needs of the public and a big picture development concept that keeps pace with the times. The second is the integration of the field of library intelligence with new technologies and other disciplines. The third is the comprehensive evaluation of scholars and institutions by data intelligence.

The research on the application of Altmetrics is still in the exploration stage, and the data, methods and conclusions used in this study also have certain limitations, mainly.

First, the data is not complete: this paper only selects papers from WOS, a platform, as the research object; the literature reviewed is mainly from foreign countries, and the limitation of research languages may have an impact on the analysis of research hotspots in the subject area.

Second, there are certain limitations in the selection of indicators. altmetric.com's data has been relatively complete, and the indicator values of highly cited literature can be obtained, but the coverage breadth and intensity of the obtained indicator data for some academic communication platforms will be 
smaller, resulting in a less comprehensive selection of indicators.

Research and analysis in the field of library and information science is a huge and long-term task, and future research needs to continue to strengthen the study, while the next discussion and research can be conducted.

\section{Conclusions}

The contribution of this paper is divided into two points:

1) Altmetrics related research that identifies research hotspots in the field of library intelligence.

2) The comprehensive impact evaluation index system is used to screen out high-impact literature in this field, and the scientific knowledge mapping software is used to visualize and analyze the research hotspots in the field of library and information science and try to discover potential hotspots in library intelligence.

\section{Conflicts of Interest}

The authors declare no conflicts of interest regarding the publication of this paper.

\section{Funds}

This paper is one of the research results of Jiangsu Provincial Social Science Foundation project "Altmetrics-based Research on Frontier Identification and Application of Scientific Research" (project number: 19TQC002).

\section{References}

[1] Priem, J., Taraborelli, D., Groth, P. and Neylon, C. (2010) Altmetrics: A Manifesto. http://altmetrics.org/manifesto

[2] Tian, D.F. and Wei, R.B. (2018) Analysis of International Information Science and Librarianship Research Hotspots in 2017. Modern Intelligence, 38, 125-129.

[3] Liu, Y.S., Zhang, H.T.A., Xu, H.L., et al. (2019) Analysis of Research Hotspots and Frontiers in the Field of Librarianship and Information Science in Foreign Countries in the Past Three Years. Modern Intelligence, 39, 168-177.

[4] Zhao, R.Y. and Yu, B. (2019) Comparative Analysis of International Library Intelligence Research Hotspots in the Past Three Years. Intelligence Science, 37, 3-9.

[5] Wang, S.G., Bu, Y. and Zhang, G. (2017) Bibliometric and Content Analysis of Papers Related to Research Methods in the Field of Library and information science in China (1981-2015). Library Journal, 36, 4-13.

[6] Hu, L. (2018) An Analysis of the Current Situation and Hotspots of Domestic Library Intelligence Research from 2012-2016-An Econometric Analysis Based on 13 Core Chinese Graphical Journals. Library Work and Research, 2018, 67-76.

[7] Si, L., Chen, J.M., Ma, T.Y., et al. (2019) An Empirical Study on the Application and Evolution of Library Intelligence Research Methods in China in the Past Five Years-A Statistical Analysis Based on Five Journals. Library, 2019, 15-21.

[8] Chai, H. and Ruan, J.H. (2019) Analysis of the Current Status of Research in the 
Discipline of "Library, Intelligence and Archives Management" Based on the National Foundation Projects from 2013 to 2017. Intelligence Science, 37, 163-169.

[9] Zhao, R.H. (2019) Analysis of Research Hotspots and Development Trend of Librarianship in China-Statistics Based on the National Social Science Foundation Projects from 2015-2019. Librarianship Research, 2019, 2-9.

[10] Jarvelin, K. and Vakkari, P. (1993) The Evolution of Library and Information Science 1965-1985: A Content Analysis of Journal Articles. Information Processing \& Management, 29, 129-144. https://doi.org/10.1016/0306-4573(93)90028-C

[11] Figuerola, C.G., Marco, F.J.G. and Pinto, M. (2017) Mapping the Evolution of Library and Information Science (1978-2014) Using Topic Modeling on LISA. Scientometrics, 112, 1507-1535. https://doi.org/10.1007/s11192-017-2432-9

[12] García-Marco, F.-J., Figuerola, G.G. and Pinto, M. (2020) Analysis of the Thematic Evolution of Research on Information and Documentation in Spanish in the LISA Database Using Thematic Modeling (1978-2019). El Profesional de la Información, 29, 1-22.

[13] Mokhtarpour, R. and Khasseh, A.A. (2020) Twenty-Six Years of LIS Research Focus and Hot Spots, 1990-2016: A Co-Word Analysis. Journal of Information Science, 2020, 165. https://doi.org/10.1177/0165551520932119

[14] Uzun, A. (2002) Library and Information Science Research in Developing Countries and Eastern European Countries: A Brief Bibliometric Perspective. International Information \& Library Review, 34, 21-33. https://doi.org/10.1080/10572317.2002.10762561

[15] Olmeda-Gómez, C., Ovalle-Perandones, M.-A. and Perianes-Rodriguez, A. (2017) Co-Word Analysis and Thematic Landscapes in Spanish Information Science Literature 1985-2014. Scientometrics, 113, 195-217. https://doi.org/10.1007/s11192-017-2486-8

[16] Qiu, J.P. (2007) Information Econometrics. Wuhan University Press, Wuhan, 192-193.

[17] Ma, F.-C. and Li, Z.-Y. (2020) Prospects for the Development of China's Library and Intelligence Disciplines in the Context of the New Liberal Arts. Chinese Journal of Library Science, 46, 4-15. 